\title{
Prevalence and Clinical Features of Atopic Dermatitis in China
}

\author{
Xin Wang, ${ }^{1,2}$ Lin-Feng Li, ${ }^{1}$ Da-yu Zhao, ${ }^{2}$ and Yi-wei Shen ${ }^{2}$ \\ ${ }^{1}$ Department of Dermatology, Beijing Friendship Hospital, Capital Medical University, Beijing 100050, China \\ ${ }^{2}$ Department of Dermatology, Beijing Shijitan Hospital, Capital Medical University, Beijing 100038, China
}

Correspondence should be addressed to Lin-Feng Li; zoonli@sina.com

Received 10 July 2016; Revised 25 September 2016; Accepted 13 October 2016

Academic Editor: Rachid Tazi-Ahnini

Copyright (C) 2016 Xin Wang et al. This is an open access article distributed under the Creative Commons Attribution License, which permits unrestricted use, distribution, and reproduction in any medium, provided the original work is properly cited.

\begin{abstract}
Background. The epidemiology of atopic dermatitis (AD) in Chinese outpatients is yet to be clarified. Objectives. To investigate population-based prevalence and clinical features of AD in Chinese outpatients. Methods. A multicenter cross-sectional study was conducted in outpatients with eczema or dermatitis from 39 tertiary hospitals in 15 provinces. Results. This study included 682 patients diagnosed with $\mathrm{AD}$, with the mean age of $28.8 \pm 20.1$ years and the median course of $5.3 \pm 6.9$ years. AD patients had more severe itching $(30.4 \%$ versus $13.8 \%, p<0.001)$ and clinically suspected bacterial infection $(21.7 \%$ versus $16.1 \%, p<0.001)$ than those of other types of dermatitis. Older patients were more susceptible to have a history of flexion dermatitis $(p<0.001)$, bacterial infection $(p=0.005)$, and severe itching $(p<0.001)$. Outpatients with clinically suspected bacterial infection had 3.53 fold increased risk of AD than those without it $(p<0.001)$. The morbidity rate of $\mathrm{AD}$ in the $\left(20-25^{\circ} \mathrm{N}\right)$ region is 2.86 times higher than that in the $\left(40-45^{\circ} \mathrm{N}\right)$ region [OR (95\% CI): $\left.0.352(0.241-0.514), p<0.001\right]$. Conclusions. AD is characterized by unique clinical/demographic features. Bacterial infection and latitude region may have an impact on the incidence of AD in China.
\end{abstract}

\section{Introduction}

Atopic dermatitis $(\mathrm{AD})$ is a type of dermatitis (inflammation of the skin), resulting in itchy, red, swollen, and cracked skin. As a common dermal condition, the incidence of $\mathrm{AD}$ is increasing annually worldwide including China. A recent systematic review of 69 cross-sectional and cohort studies has confirmed that $\mathrm{AD}$ is a worldwide phenomenon with a lifetime prevalence of $>20 \%$ in many countries [1]. The prevalence of childhood $\mathrm{AD}$ is ranging from $15 \%$ to $30 \%$ and from $2 \%$ to $10 \%$ of adult $\mathrm{AD}$ in industrialized countries [2]. As we all know, many studies have shown that the prevalence of this disease among children has increased substantially over recent years [3]. In China, the prevalence of $\mathrm{AD}$ in students aged 6-20 years was only $0.7 \%$ in 2000 [4]; however, it had reached up to $8.3 \%$ (95\% CI: 7.6\%-9.1\%) in children aged 3 to 6 years in Shanghai in 2012 [5]. Intriguingly, few studies have paid attention to $\mathrm{AD}$ patients of all ages, despite the fact that the occurrence of $\mathrm{AD}$ among adults has been shown to significantly affect socioeconomic conditions in both Asian and Western countries [6]. A recent survey has investigated clinical features of adult/adolescent (12 years and over) $\mathrm{AD}$ [7], but the epidemiology of $\mathrm{AD}$ at all ages in China is yet to be elucidated. Therefore, the purpose of the current study is to determine the actual prevalence and clinical features of $\mathrm{AD}$ at all ages in outpatients with dermatitis and eczema across large tertiary hospitals in China.

\section{Methods}

2.1. Study Population. This study has been approved by Institutional Review Board (IRB) committee at each hospital involved in this study. Oral informed consent was acquired from each participant before enrollment. All procedures were conducted according to the guidelines approved by the ethics committee at each hospital. Demographic and clinical information was acquired from patients who were treated in the respective hospitals from July 1 to September 30, 2014. Patients were diagnosed with AD in 39 tertiary hospitals of 15 provinces and municipalities in mainland China, including Guangdong, Chongqing, Hunan, Jiangxi, Henan, Zhejiang, Shanghai, Hubei, Jiangsu, Anhui, Shanxi, Beijing, Tianjin, Shandong, and Liaoning Province, that generally represented most regions of China. 
2.2. Diagnostic Criteria of $A D$. All dermatologists involved in this study have abundant experience in clinical diagnosis and treatment for $\mathrm{AD}$ and have been trained in a standardized manner before the start of the project. First, each subject was inspected by a dermatologist independently. Then, a questionnaire survey was conducted by dermatologists after 10-15 minutes' dermatological physical examination. All diagnostic criteria mentioned in Williams diagnostic criteria [8] were integrated and recorded in detail; the parents or guardians had filled the consent forms for children patients. According to the questionnaire and physicians' evaluation, a comprehensive diagnosis of $\mathrm{AD}$ was made based on the gold standard "Williams diagnostic criteria" after investigation. Moreover, all patients with other types of dermatitis and eczema seen in the same period by the same investigators served as controls. Other types of dermatitis and eczema such as irritant contact dermatitis (ICD), widespread eczema, hand eczema, allergic contact dermatitis (ACD), neurodermatitis, seborrheic dermatitis, nummular eczema, asteatotic eczema, photo-contact dermatitis, autosensitization eczema, dyshidrotic eczema, and stasis dermatitis were classified based on International Classification of Diseases (ICD-10) [9] and diagnosed accordingly based on medical history and clinical features. No laboratorial test was performed for dermatologists to make the diagnosis.

2.3. Data Collection. All enrolled patients had completed a specific survey containing questionnaires regarding their general demographic characteristics, disease duration, severity of itching, lesion's distribution, type of skin lesion, and medical history. Itch was evaluated and divided into 4 levels: (i) no itching; (ii) mild itching that interrupted neither daily activities nor sleep of the participant; (iii) moderate itching that interrupted daily activities but not affected sleep; and (iv) severe itching that affected both daily activities and sleep of the participant. History of allergic disease, dry skin, infantile eczema, and flexion dermatitis was also recorded. Allergic diseases included asthma, allergic rhinitis, allergic conjunctivitis, and AD. Secondary bacterial infection was clinically suspected if superficial pustules, prudent exudation, or yellow colored crust was detected.

2.4. Statistical Analysis. Statistical analyses were processed by SPSS software (version 17.0). Differences in age and disease course between AD groups were analyzed by $t$-tests. Differences in age and disease course between AD among different age groups were analyzed by One-Way ANOVA. Differences in gender, all kinds of medical history, and clinically suspected bacterial infection between AD groups were analyzed by Chi-square tests. Itching grade between $\mathrm{AD}$ groups was analyzed by Chi-square test. Age, gender, and other significant factors were adjusted in Binary Logistic regression models for odds ratio (OR) and 95\% confidence interval (CI) estimation. All analyses were two-sided with a significant level of $p<0.05$.
TABLE 1: Comparison of AD with other types of dermatitis.

\begin{tabular}{|c|c|c|}
\hline Variables & $\begin{array}{c}\mathrm{AD} \\
(N=682)\end{array}$ & $\begin{array}{c}\text { Other types of } \\
\text { dermatitis }(N=8076)\end{array}$ \\
\hline $\begin{array}{l}\text { Median age* (years, mean } \\
\pm \text { SD) }\end{array}$ & $28.8 \pm 20.1$ & $36.7 \pm 18.4$ \\
\hline $\begin{array}{l}\text { Median course }{ }^{*} \text { (years, } \\
\text { mean } \pm \text { SD) }\end{array}$ & $5.3 \pm 6.9$ & $2.8 \pm 4.8$ \\
\hline Gender (men) $(n, \%)$ & $368(54.0)$ & $4067(50.4)$ \\
\hline $\begin{array}{l}\text { History of allergic disease }{ }^{* *} \\
(n, \%)\end{array}$ & $535(78.4)$ & $750(9.3)$ \\
\hline History of asthma** $(n, \%)$ & $134(19.6)$ & $165(2.0)$ \\
\hline $\begin{array}{l}\text { History of allergic } \\
\text { rhinitis }^{* *}(n, \%)\end{array}$ & $184(27.0)$ & $289(3.6)$ \\
\hline $\begin{array}{l}\text { History of allergic } \\
\text { conjunctivitis }^{* *}(n, \%)\end{array}$ & $167(24.5)$ & $223(2.8)$ \\
\hline History of $\mathrm{AD}^{* *}(n, \%)$ & $87(12.8)$ & $100(1.2)$ \\
\hline History of dry skin ${ }^{* *}(n, \%)$ & $502(73.6)$ & $1388(17.2)$ \\
\hline $\begin{array}{l}\text { History of flexion } \\
\text { dermatitis }^{* *}(n, \%)\end{array}$ & $437(64.1)$ & $441(5.5)$ \\
\hline $\begin{array}{l}\text { History of infantile } \\
\text { eczema }^{* *}(n, \%)\end{array}$ & $285(41.8)$ & $534(6.6)$ \\
\hline \multicolumn{3}{|l|}{ Itching ${ }^{* *}$} \\
\hline No $(n, \%)$ & $0(0.0)$ & $259(3.2)$ \\
\hline Mild $(n, \%)$ & $119(17.4)$ & $2510(31.1)$ \\
\hline Moderate $(n, \%)$ & $356(52.2)$ & 4189 (51.9) \\
\hline Severe $(n, \%)$ & $207(30.4)$ & $1118(13.8)$ \\
\hline $\begin{array}{l}\text { Clinically suspected } \\
\text { bacterial infection }^{* *}(n, \%)\end{array}$ & $148(21.7)$ & $1302(16.1)$ \\
\hline
\end{tabular}

\section{Results}

3.1. Demographic Characteristics of $A D$. Data were collected on a total of 8,758 outpatients with dermatitis and eczema. Overall, the prevalence of AD in outpatients was $7.8 \%(95 \%$ CI: 7.3-8.4). The comparison of demographic and clinical characteristics between $\mathrm{AD}$ and other types of dermatitis is summarized in Table 1 . The mean age of AD patients was lower than those of other types of dermatitis $(28.8 \pm 20.1$ versus $36.7 \pm 18.4$ years, $p<0.001)$, but median course was much longer $(5.3 \pm 6.9$ versus $2.8 \pm 4.8$ years, $p<0.001)$. There is no difference in gender make-up $(p=0.071)$.

3.2. Clinical Characteristics of AD. $78.4 \%$ AD patients had history of allergic disease, which was significantly higher than that of other types of dermatitis $(9.3 \%, p<0.001)$. Furthermore, history of dry skin, flexion dermatitis, and infantile eczema were more frequent than those of other types of dermatitis $(73.6 \%$ versus $17.2 \%, 64.1 \%$ versus $5.5 \%$, and $41.8 \%$ versus $6.6 \%, p<0.001)$. In terms of the severity of itching, the AD patients may be more severe than that of other types of dermatitis patients $(30.4 \%$ versus $13.8 \%, p<0.001)$. The clinically suspected bacterial infection in AD patients was statistically significant higher than that of other types of dermatitis patients $(21.7 \%$ versus $16.1 \%, p<0.001)$. 


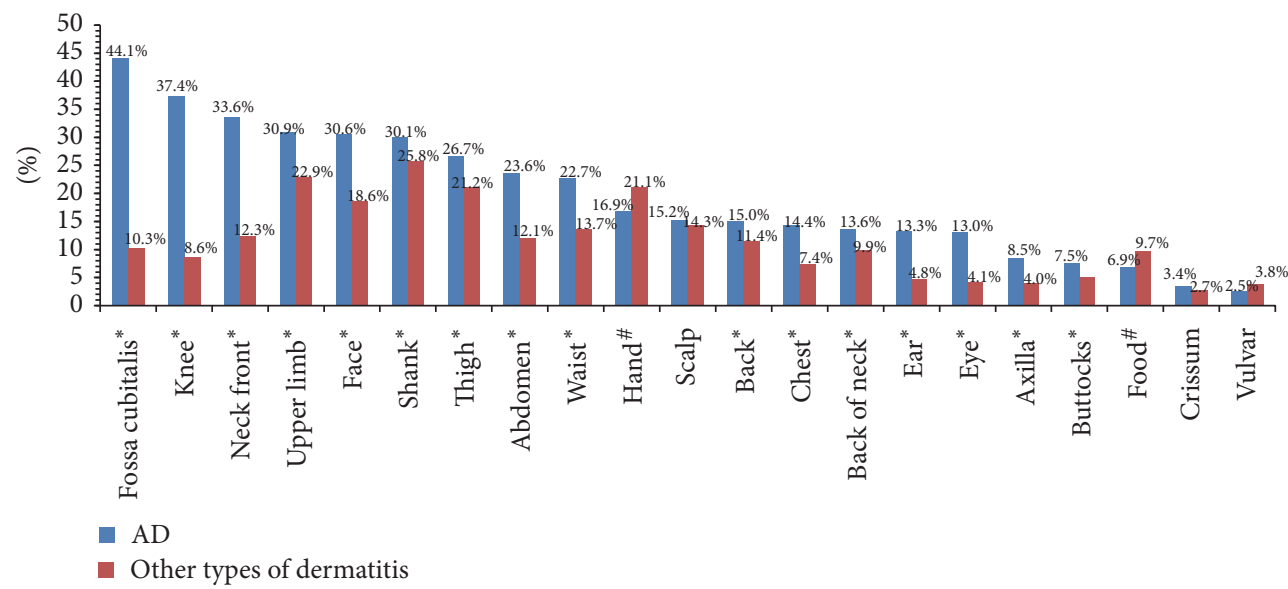

Figure 1: Lesions distribution of $\mathrm{AD}$ and other types of dermatitis. ${ }^{*}$ This body location was more involved in $\mathrm{AD}$ than other types of dermatitis, $p<0.05$, Chi-square test. ${ }^{\#}$ This body location was more involved in other types of dermatitis than $\mathrm{AD}, p<0.05$, Chi-square test.

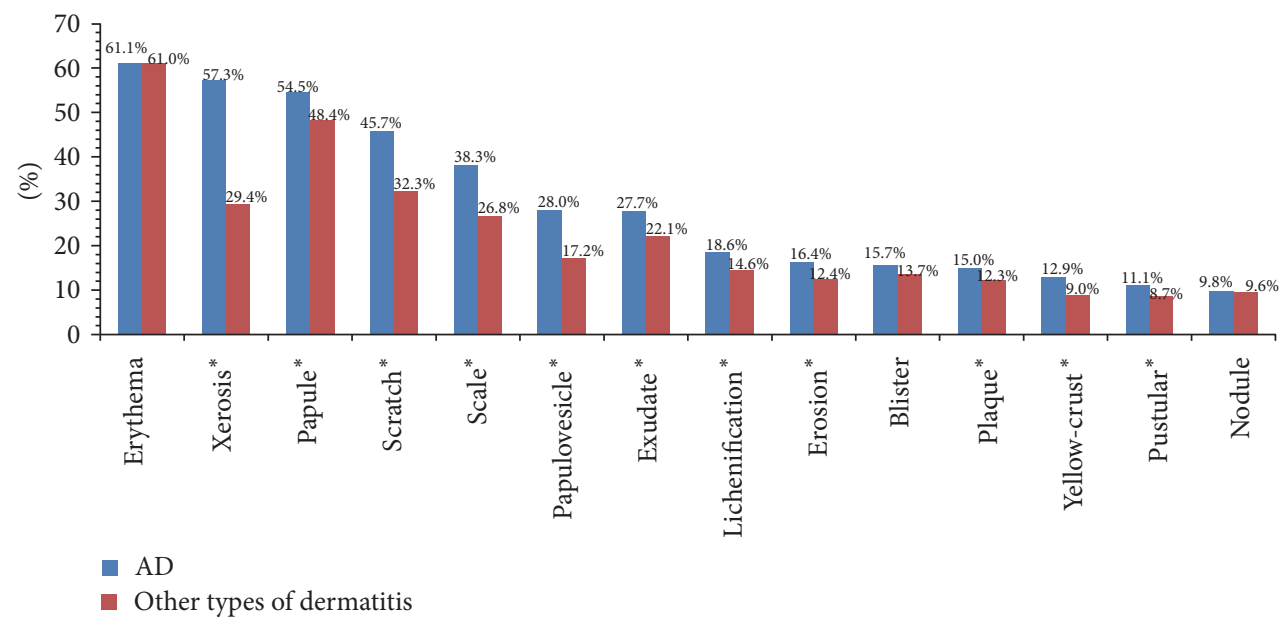

FIGURE 2: Skin lesion types of AD and other types of dermatitis. *This skin lesion type was more common in AD than other types of dermatitis, $p<0.05$, Chi-square test.

The top five frequent sites involved in $\mathrm{AD}$ were fossa cubitalis (44.1\%), knee (37.4\%), neck front (33.6\%), upper limb (30.9\%), and face (30.6\%). The hand $(21.1 \%$ versus $16.9 \%$, $p<0.05)$ and foot $(9.7 \%$ versus $6.9 \%, p<0.05)$ were more frequent sites involved in other types of dermatitis than $\mathrm{AD}$ and little variation on scalp, crissum, and vulvar between them $(14.3 \%$ versus $15.2 \%, 2.7 \%$ versus $3.4 \%$, and $3.8 \%$ versus $2.5 \%$, resp., $p>0.05$ ); however, other body locations were much less involved in other types of dermatitis (Figure 1).

The most common skin lesion types of AD were erythema (61.1\%), xerosis (57.3\%), papule (54.5\%), scratch (45.7\%), and scale $(38.3 \%)$. All skin lesion types were more common in AD than other types of dermatitis, especially in xerosis, scratch, and scale $(57.3 \%$ versus $29.4 \%, 45.7 \%$ versus $32.3 \%$, and $38.3 \%$ versus $26.8 \%$, resp., $p<0.05$ ), but not in erythema, blister, and nodule (61.1\% versus $61.0 \%, 15.7 \%$ versus $13.7 \%$, and $9.8 \%$ versus $9.6 \%, p>0.05$ ) (Figure 2 ).

3.3. The Stratifying Analysis Based on Age Groups. Three stages of $\mathrm{AD}$ are proposed including infantile $\mathrm{AD}$ (age $<2$ years), childhood $\mathrm{AD}$ (age 2-12), and adolescent/adult $\mathrm{AD}$ (age $>12$ years). There were no significant statistical differences between three groups with respect to their sex $(p=$ $0.58)$, history of allergic rhinitis $(p=0.87)$, dry skin $(p=$ $0.78)$, and $\operatorname{AD}(p=0.18)$. And there were high at both ends but low in the middle like a " $U$ " shaped curve in the field of history of allergic disease $(p=0.005)$, asthma $(p<0.001)$, and allergic conjunctivitis $(p=0.024)$. As AD patients get older, they have higher proportion of history of flexion dermatitis $(p<0.001)$, clinically suspected bacterial infection $(p=0.005)$, and severe itching $(p<0.001)$, but lower proportion of history of infantile eczema $(p<0.001)$ (Table 2$)$.

3.4. The Multivariable Logistic Regression Analysis of AD and Related Factors. In multivariable logistic regression analysis of $\mathrm{AD}$ and related factors, the independent indicators included age, disease duration, latitude, and bacterial infection.

It has indicated that the probability of developing $\mathrm{AD}$ increases $2.2 \%$ and $3.6 \%$, respectively, as age and disease 
TABLE 2: Comparison of AD with different ages.

\begin{tabular}{|c|c|c|c|}
\hline Variables & $\begin{array}{l}<2 \text { years } \\
(N=63)\end{array}$ & $\begin{array}{l}2-12 \text { years } \\
(N=135)\end{array}$ & $\begin{array}{l}>12 \text { years } \\
(N=484)\end{array}$ \\
\hline $\begin{array}{l}\text { Median age* (years, } \\
\text { mean } \pm \text { SD) }\end{array}$ & $1.3 \pm 0.7$ & $7.3 \pm 3.1$ & $38.4 \pm 15.7$ \\
\hline $\begin{array}{l}\text { Median course }{ }^{*} \\
(\text { years, mean } \pm S D)\end{array}$ & $0.7 \pm 0.7$ & $4.5 \pm 3.5$ & $6.1 \pm 7.8$ \\
\hline Gender (men) $(n, \%)$ & $38(60.3)$ & $72(53.3)$ & $258(53.3)$ \\
\hline $\begin{array}{l}\text { History of allergic } \\
\text { disease }^{* *}(n, \%)\end{array}$ & $47(74.6)$ & $93(68.9)$ & $395(81.6)$ \\
\hline $\begin{array}{l}\text { History of asthma** } \\
(n, \%)\end{array}$ & $4(6.3)$ & $5(3.7)$ & $88(8.2)$ \\
\hline $\begin{array}{l}\text { History of allergic } \\
\text { rhinitis }(n, \%)\end{array}$ & $12(19.0)$ & $29(21.5)$ & $106(21.9)$ \\
\hline $\begin{array}{l}\text { History of allergic } \\
\text { conjunctivitis** }(n, \%)\end{array}$ & $11(17.5)$ & 15 (11.1) & $104(21.5)$ \\
\hline History of $\mathrm{AD}(n, \%)$ & $8(12.7)$ & $11(8.1)$ & $31(6.4)$ \\
\hline $\begin{array}{l}\text { History of dry skin }(n, \\
\%)\end{array}$ & $44(69.8)$ & $100(74.1)$ & $358(74)$ \\
\hline $\begin{array}{l}\text { History of flexion } \\
\text { dermatitis }^{* *}(n, \%)\end{array}$ & $25(39.7)$ & $88(65.2)$ & $324(66.9)$ \\
\hline $\begin{array}{l}\text { History of infantile } \\
\text { eczema** }^{* *}(n, \%)\end{array}$ & $60(95.2)$ & $117(86.7)$ & $108(22.3)$ \\
\hline \multicolumn{4}{|l|}{ Itching $^{* *}$} \\
\hline Mild $(n, \%)$ & $10(15.9)$ & 15 (11.1) & $94(19.4)$ \\
\hline Moderate $(n, \%)$ & $44(69.8)$ & $85(63)$ & $227(46.9)$ \\
\hline Severe $(n, \%)$ & $9(14.3)$ & 35 (25.9) & $163(33.7)$ \\
\hline $\begin{array}{l}\text { Clinically suspected } \\
\text { bacterial infection** } \\
(n, \%)\end{array}$ & $8(12.7)$ & $17(12.6)$ & $115(23.8)$ \\
\hline
\end{tabular}

duration increased by one year. The outpatients with clinically suspected bacterial infection may have 3.532-times increased risk of $\mathrm{AD}$ than those without it. Thirty-nine hospitals were divided into 5 groups based on their latitude; the mean summer temperature increased as latitude decreased. The morbidity rate of $\mathrm{AD}$ in the lowest latitude region $20-25^{\circ} \mathrm{N}$ is 2.86 times higher than that in the highest latitude region $40-45^{\circ} \mathrm{N}$ (Table 3 ).

\section{Discussion and Conclusion}

$\mathrm{AD}$ is a global public health concern considering its great influence on people's life and social economy. There have been numerous epidemiological studies of $\mathrm{AD}$ using questionnaires, but very few have been performed by dermatologists' physical examinations owing to being time consuming and labor cost [10]. In order to guarantee uniformity of diagnosis, a panel of experienced dermatologists was involved in physical examination and detailed medical records. The present study has provided the first outpatient-based prevalence of $\mathrm{AD}$ at all ages in dermatology clinics in mainland China, with several interesting findings.

Our research shows that the incidence of AD in outpatients $(7.8 \%)$ has been raised in recent years, much higher
TABLE 3: Binary Logistic regression of AD and related factors.

\begin{tabular}{lccc}
\hline & OR & $95 \%$ CI & $p$ \\
\hline Age & 1.022 & $1.009-1.035$ & 0.001 \\
Disease duration & 1.036 & $1.018-1.053$ & $<0.001$ \\
Gender & & & \\
$\quad$ Male & 1.0 (ref.) & & \\
$\quad$ Female & 0.894 & $0.758-1.055$ & 0.183 \\
Latitude & & & \\
$20-25^{\circ} \mathrm{N}$ & 1.0 (ref.) & & \\
$25-30^{\circ} \mathrm{N}$ & 0.733 & $0.511-1.051$ & 0.091 \\
$30-35^{\circ} \mathrm{N}$ & 0.821 & $0.637-1.059$ & 0.129 \\
$35-40^{\circ} \mathrm{N}$ & 0.858 & $0.655-1.122$ & 0.263 \\
$\quad 40-45^{\circ} \mathrm{N}$ & 0.352 & $0.241-0.514$ & $<0.001$ \\
Clinically suspected & & & \\
bacterial infection & & & \\
$\quad$ No & 1.0 (ref.) & & \\
$\quad$ Yes & 3.532 & $2.779-4.489$ & $<0.001$ \\
\hline
\end{tabular}

Thirty-nine hospitals were divided into 5 groups based on their latitude: (i) $20^{\circ} 01^{\prime}-25^{\circ} \mathrm{N}$, Guangdong Province; (ii) $25^{\circ} 01^{\prime}-30^{\circ} \mathrm{N}$, Chongqing, Hunan, and Jiangxi Provinces; (iii) $30^{\circ} 01^{\prime}-35^{\circ} \mathrm{N}$, Henan, Zhejiang, Shanghai, Hubei, Jiangsu, Anhui, and Shanxi Provinces; (iv) $35^{\circ} 01^{\prime}-40^{\circ}$, Beijing, Tianjin, and Shandong Province; and (v) $40^{\circ} 01^{\prime}-45^{\circ} \mathrm{N}$, Liaoning Province.

than that from our previous study $(2.3 \%, 14 / 599)$ [11]. The higher prevalence and longer duration of AD compared with other types of dermatitis have indicated that more attention should be paid to this disease. Although the occurrence of $\mathrm{AD}$ may be associated with genetic factors [12, 13], a recent markedly increased incidence rate is more likely to be attributed to environmental factors [14-16] and changing lifestyles, such as air/water/soil pollution, an increase in aeroallergens, frequent bathing, and regular use of soap. In addition, the awareness of $\mathrm{AD}$ by dermatologists and patients may also contribute to this phenomenon. In China, the symmetrical eczematous dermatitis tends to be diagnosed as eczema in the past decades, indicating an overdiagnosed eczema and underdiagnosed AD [7]. Until recent years, we began to pay attention to $\mathrm{AD}$ and have improved the accuracy of diagnosis.

We have observed significant differences in terms of medical history between $\mathrm{AD}$ and other types of dermatitis. It has been widely accepted that $\mathrm{AD}$ is a systemic disease, not only dermal manifestations. AD in infancy is thought to contribute to the development of subsequent allergies known as atopic march [17]; more than half of children with moderate to severe $\mathrm{AD}$ would develop allergic rhinitis and/or asthma [18]. Up to $78.4 \%$ of AD patients had a history of allergic diseases, indicating that dermatologists should focus on medical history when a patient has symmetrical eczematous dermatitis. As AD patients were getting older, a "U" shaped curve was observed between age groups regarding a history of allergic diseases, asthma, and allergic conjunctivitis (Table 2). This phenomenon may confer the characteristics of allergic diseases. A study in Algeria has observed significant differences in the prevalence of asthma between different age 
groups, the highest in children aged $<16$ and in the oldest group ( $>54$ years) [19]. Further investigation is required to explore mechanisms and significance of this phenomenon.

The proportion of AD patients with a history of flexion dermatitis or severe itching was positively associated with age (Table 2). Undoubtedly, scratching is one reason for this observation. This means a coexistent relationship between a history of flexion dermatitis and severe itching, which creates a vicious feedback loop of flexion dermatitis-severe itchingscratching.

Our study has indicated that $\mathrm{AD}$ is prone to clinically suspected bacterial infection, especially in older patients. A major cause for stratum corneum barrier disruption in $\mathrm{AD}$ is attributed to loss-of-function mutations in FLG gene that encodes filaggrin, a structural protein in keratinocytes/corneocytes, which allows outside-in penetration of foreign antigens and subsequent sensitization [20]. The AD patients with barrier-disrupted skin are more susceptible to bacterial infection, which in turn increases the severity of AD. In China, bacterial culture was not usually performed in clinics. This survey may have greater significance in clinical practice because how doctors define secondary bacterial infection would affect the choice of antibiotics.

Compared to other types of dermatitis, $\mathrm{AD}$ has more extensive body location involvement, especially in fossa cubitalis, knee, and neck front (44.1\% versus $10.3 \%, 37.4 \%$ versus $8.6 \%$, and $33.6 \%$ versus $12.3 \%$, resp., Figure 1 ). The reason for this difference is unclear, probably related to thickness of cut-in and frequency of friction, for these parts of the body have thinner stratum corneum (SC) and are vulnerable to friction with the limbs activity. Conversely, the body locations with thick SC like hand and foot are not susceptible to suffer from $\mathrm{AD}$, which is characterized by epidermal barrier dysfunction. $\mathrm{AD}$ has more diverse skin lesion types than other types of dermatitis, especially in xerosis, scratch, and scale (Figure 2). This has emphasized the importance of using emollients in $\mathrm{AD}$ patients, which is well tolerated and mainly in an attempt to restoring or replacing the intrinsic and/or externally induced abnormalities of the skin [21]. Those disparities of AD and other types of dermatitis are to some extent helpful to diagnosis in clinical practice.

Multiple factorial analysis has suggested a strong trend towards a decrease in the incidence of $\mathrm{AD}$ with an increase in latitude (Table 3), demonstrating dual roles of geography and economy. A large-scale prospective, longitudinal cohort study has evaluated the effect of long-term weather patterns on the severity of eczema symptoms in children and revealed that geographic areas with increased temperature, sun exposure (total, UVA, and UVB), and humidity were associated with poorly controlled disease [22]. It is possible that warm and humid weather leads to enhanced sweating, which has an irritant effect on the skin [23, 24]. The economic and living condition in southern China is becoming better than that in northern China, including more fastidious hygiene, better living conditions such as air conditioners, and higher standards of medical care. It is logistic to infer that economic condition may contribute to the higher rate of $\mathrm{AD}$ in southern China.
Several limitations should be considered when interpreting our results: (i) all of the 39 participating centers were tertiary referral hospitals located in 15 provincial capital or central cities, and most patients visiting these hospitals were in a better financial condition and medical insurance than the average people in China; (ii) the sample size in the present study was relatively small considering the total 1.3 billion Chinese population, and (iii) although we had demonstrated that clinically suspected secondary bacterial infection was quite reliable [25], bacterial culture is guaranteed to confirm the current findings. All these factors may lead to inevitable selection bias.

In conclusion, this research highlights atopic dermatitis with unique clinical characteristics, which has become a common dermatologic disease in China. Importantly, secondary bacterial infection and latitude region may have a profound impact on the incidence of AD.

\section{Competing Interests}

The authors declare that there is no conflict of interests regarding the publication of this paper.

\section{Acknowledgments}

This research is supported by Dermatology Committee, Chinese Association of Integrative Medicine.

\section{References}

[1] I. A. G. Deckers, S. McLean, S. Linssen, M. Mommers, C. P. van Schayck, and A. Sheikh, "Investigating international time trends in the incidence and prevalence of atopic eczema 1990-2010: a systematic review of epidemiological studies," PLOS ONE, vol. 7, no. 7, Article ID e39803, 2012.

[2] T. Bieber, "Atopic dermatitis," The New England Journal of Medicine, vol. 358, no. 14, pp. 1483-1494, 2008.

[3] M. I. Asher, S. Montefort, B. Björkstén et al., "Worldwide time trends in the prevalence of symptoms of asthma, allergic rhinoconjunctivitis, and eczema in childhood: ISAAC phases one and three repeat multicountry cross-sectional surveys," The Lancet, vol. 368, no. 9537, pp. 733-743, 2006.

[4] H. Gu, Y. Yan, and C. Chen, "Epidemiology of atopic dermatitis in 6-20 year-old population in China," Chinese Journal of Dermatology, vol. 6, no. 1, pp. 379-382, 2000.

[5] F. Xu, S. Yan, F. Li et al., "Prevalence of childhood atopic dermatitis: an urban and rural community-based study in Shanghai, China," PLoS ONE, vol. 7, no. 5, Article ID e36174, 2012.

[6] K. Nishioka, "Atopic eczema of adult type in Japan," Australasian Journal of Dermatology, vol. 37, no. 1, pp. S7-S9, 1996.

[7] P. Liu, Y. Zhao, Z. L. Mu, Q. J. Lu, L. Zhang, and X. Yao, "Clinical features of adult/adolescent atopic dermatitis and chinese criteria for atopic dermatitis," Chinese Medical Journal, vol. 129, no. 7, pp. 757-762, 2016.

[8] H. C. Williams, "Diagnostic criteria for atopic dermatitis," The Lancet, vol. 348, no. 9038, pp. 1391-1392, 1996.

[9] "International statistical classification of diseases and related health problems-10th revision," World Health Organization, 2010. 
[10] H. Saeki, H. Iizuka, Y. Mori et al., "Prevalence of atopic dermatitis in Japanese elementary schoolchildren," British Journal of Dermatology, vol. 152, no. 1, pp. 110-114, 2005.

[11] L.-F. Li, G. Liu, and J. Wang, "Prognosis of unclassified eczema: A Follow-Up Study," Archives of Dermatology, vol. 144, no. 2, pp. 160-164, 2008.

[12] H. Y. Kim, E. Y. Jang, J. H. Sim et al., "Effects of family history on the occurrence of atopic dermatitis in infants," Pediatric Allergy and Respiratory Disease, vol. 19, no. 2, pp. 106-114, 2009.

[13] H. Bisgaard, L. B. Halkjær, R. Hinge et al., "Risk analysis of early childhood eczema," The Journal of Allergy and Clinical Immunology, vol. 123, no. 6, pp. 1355-1360.e5, 2009.

[14] I. J. Wang, Y. L. Guo, H. J. Weng et al., "Environmental risk factors for early infantile atopic dermatitis," Pediatric Allergy and Immunology, vol. 18, no. 5, pp. 441-447, 2007.

[15] Y. Miyake, Y. Ohya, K. Tanaka et al., "Home environment and suspected atopic eczema in Japanese infants: the Osaka Maternal and Child Health Study," Pediatric Allergy and Immunology, vol. 18, no. 5, pp. 425-432, 2007.

[16] B. Sebõk, I. Schneider, and F. Harangi, "Primary care paediatricians in baranya county," Journal of the European Academy of Dermatology and Venereology, vol. 20, no. 4, pp. 418-422, 2006.

[17] H.-M. Lee, I.-H. Park, J.-M. Shin et al., "XXIV world allergy congress 2015 Seoul, Korea. 14-17 October (2015)," World Allergy Organization Journal, vol. 9, no. 1, p. 1, 2016.

[18] H. H. Kong, J. Oh, C. Deming et al., "Temporal shifts in the skin microbiome associated with disease flares and treatment in children with atopic dermatitis," Genome Research, vol. 22, no. 5, pp. 850-859, 2012.

[19] S. Nafti, S. Taright, M. El Ftouh et al., "Prevalence of asthma in North Africa: the Asthma Insights and Reality in the Maghreb (AIRMAG) study," Respiratory Medicine, vol. 103, no. 2, pp. S2S11, 2009.

[20] A. D. Irvine, W. H. I. McLean, and D. Y. M. Leung, "Filaggrin mutations associated with skin and allergic diseases," The New England Journal of Medicine, vol. 365, no. 14, pp. 1315-1327, 2011.

[21] M. Boguniewicz and D. Y. M. Leung, "Recent insights into atopic dermatitis and implications for management of infectious complications," Journal of Allergy and Clinical Immunology, vol. 125, no. 1-3, pp. 4-13, 2010.

[22] M. R. Sargen, O. Hoffstad, and D. J. Margolis, "Warm, humid, and high sun exposure climates are associated with poorly controlled Eczema: PEER (Pediatric Eczema Elective Registry) Cohort, 2004-2012," Journal of Investigative Dermatology, vol. 134, no. 1, pp. 51-57, 2014.

[23] S. M. Langan, J. F. Bourke, P. Silcocks, and H. C. Williams, "An exploratory prospective observational study of environmental factors exacerbating atopic eczema in children," British Journal of Dermatology, vol. 154, no. 5, pp. 979-980, 2006.

[24] S. M. Langan, P. Silcocks, and H. C. Williams, "What causes flares of eczema in children?" British Journal of Dermatology, vol. 161, no. 3, pp. 640-646, 2009.

[25] L. F. Li and X. Y. Yuan, "Detection and analysis of bacteria flora in the skin of the patients with non-atopic eczematous dermatitis," Journal of Clinical Dermatology, vol. 32, no. 2, pp. 74-75, 2003. 


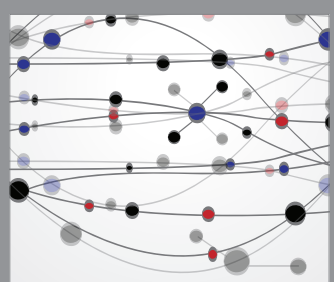

The Scientific World Journal
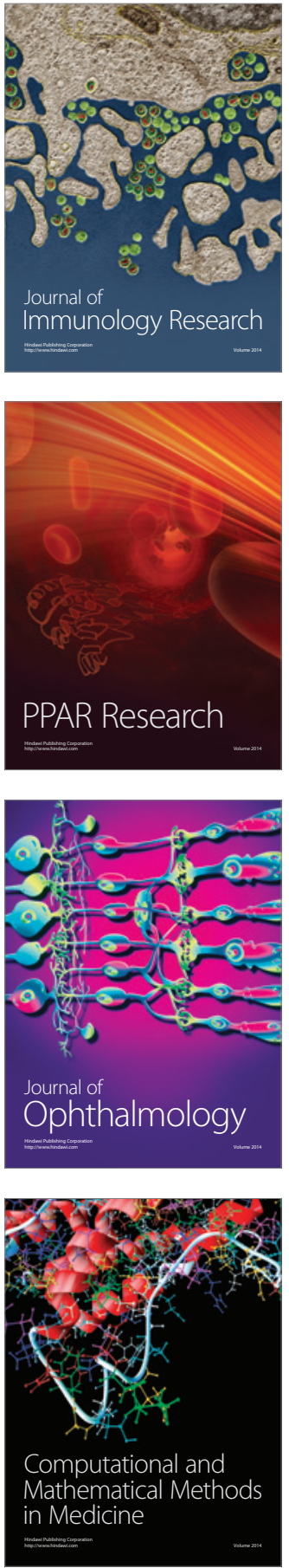

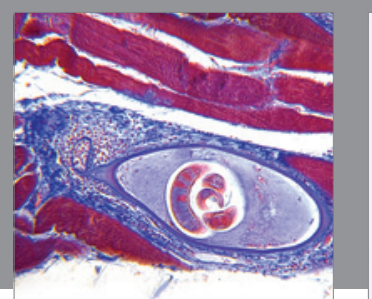

Gastroenterology Research and Practice

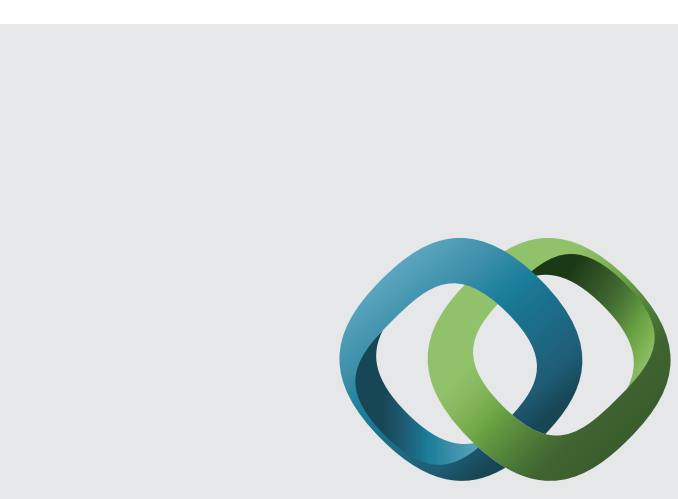

\section{Hindawi}

Submit your manuscripts at

http://www.hindawi.com
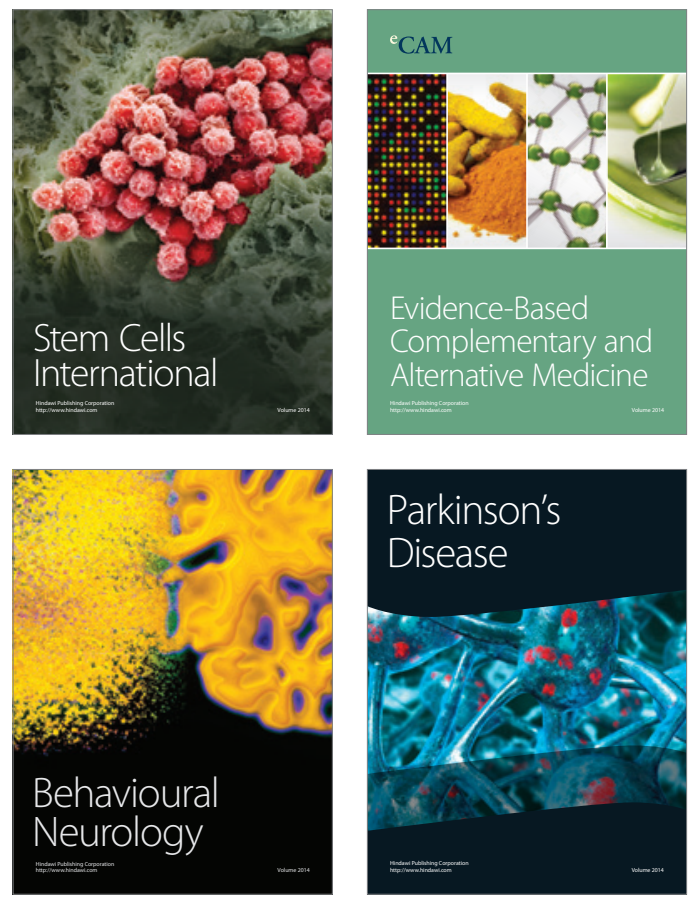
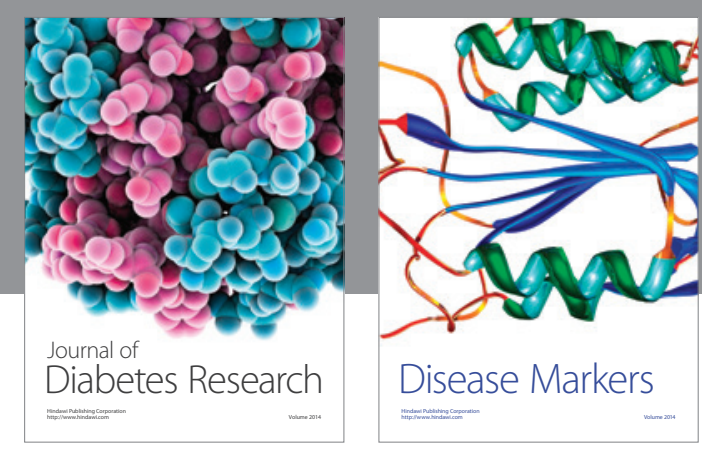

Disease Markers
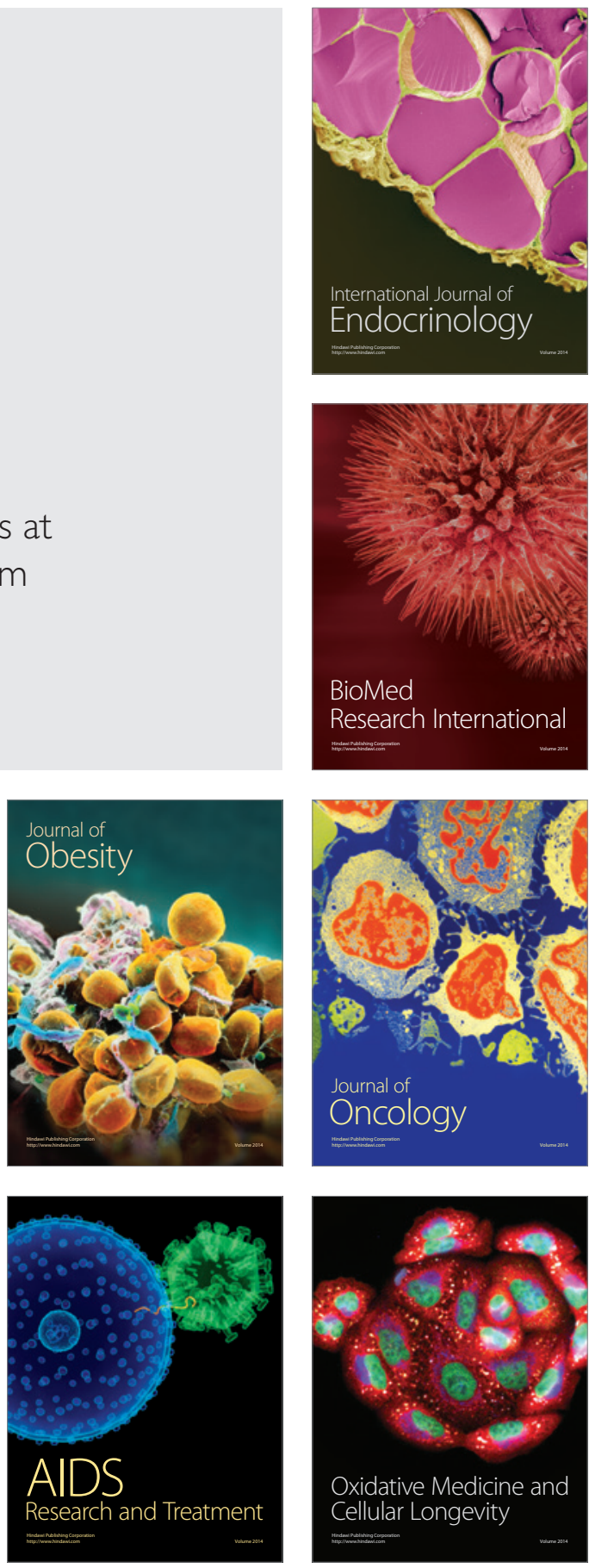